\title{
Changeover from unsignaled to signaled avoidance as a function of the changeover period duration
}

\author{
STUART CULBERTSON \\ The American University, Washington, D.C. 20016 \\ and \\ PIETRO BADIA \\ Bowling Green State University, Bowling Green, Ohio 43403
}

\begin{abstract}
A changeover procedure was used to study choice of signaled over unsignaled free operant avoidance. Four rats avoided unsignaled shock (RS-20, SS-5) on one lever but, by pressing a second (changeover) lever, they changed the condition to signaled avoidance (5-sec signal) for 60 -sec periods. After changeover responding stabilized, the changeover period was gradually reduced from 60 to as low as 5 sec. Three of the subjects continued changing over to the signaled avoidance condition until the period was reduced to below $20 \mathrm{sec}$. The fourth subject stopped changing to the signaled schedule when the changeover period was reduced to $30 \mathrm{sec}$. The reduction in changeover responding at the shorter changeover periods was attributed to subjects receiving fewer signals and more shocks.
\end{abstract}

Two procedures have been used to demonstrate that subjects will choose to avoid signaled rather than unsignaled shock. The first (Sidman, 1955) initially placed subjects on an unsignaled free-operant avoidance schedule. Then this schedule was modified so that subjects could still avoid unsignaled shock. however, if they waited $15 \mathrm{sec}$, a signal preceded shock and subjects could then avoid on a signaled schedule. Evidence is available (e.g., Keehn, 1959; Sidman, 1955; Ulrich, Holz, \& Azrin, 1964) showing that subjects consistently wait for the signal. This evidence also shows that under a signaled avoidance schedule subjects emit fewer responses and receive fewer shocks. Since subjects wait for the signal, it has been concluded that they prefer signaled to unsignaled avoidance.

Similar findings have been obtained with the procedure used by Badia, Culbertson, and Lewis (1971). In their experiments, rats avoided unsignaled shock on one lever but, by responding on a second lever, they could change the schedule to signaled avoidance for 1-min periods. Badia et al. reported that all subjects developed a high rate of responding for signaled avoidance. The behavior of subjects under the signaled condition was essentially the same as that reported by others.

There are several advantages to the procedure used by Badia et al. (1971). For one, the changeover procedure requires an active rather than passive response and, thus, allows continuous monitoring of behavior over time. The

Reprints may be obtained from Stuart Culbertson, Department of Psychology, The American University, Washington, D.C. 20016. changeover response can also be manipulated independently of the avoidance response and the particular avoidance schedule in effect. In addition, the method allows separate analyses of the various stimulus components which exist within the signaled and unsignaled avoidance paradigms.

As noted, the length of time that a changeover response produced a signaled avoidance schedule in previous research was $60 \mathrm{sec}$. The purpose of the present study was to manipulate this parameter by systematically decreasing the duration of signaled avoidance periods from 60 to $5 \mathrm{sec}$. Specific questions asked in this context were: (1) What is the lowest temporal value of each signaled period sufficient to maintain the changeover response, and (2) what changes in other variables (e.g., avoidance responses, shock rate) accompany a decrease in the duration of signaled avoidance periods?

\section{METHOD}

\section{Subjects}

Four experimentally naive female albino rats of the SpragueDawley strain (Holtzman) were used. Each subject was housed individually in a room separate from the experimental chamber and maintained with free access to food and water.

\footnotetext{
Apparatus

A Foringer self-contained acoustical box described by Badia et al. (1971) was used. Enclosed in the box was an operant conditioning chamber measuring $24 \times 25.4 \times 12.7 \mathrm{~cm}$ high. Two Foringer response levers requiring a $20 \mathrm{~g}$ base were centered $5.08 \mathrm{~cm}$ from each side along the $25.4-\mathrm{cm}$ wall and were placed $7.62 \mathrm{~cm}$ above the grid floor. The right lever served for avoidance and the left lever was used for changeover responding. A sonalert $(78 \mathrm{~dB})$ provided the preshock warning stimulus. The
} 
stimulus identifying the signaled schedule (correlated stimulus) was the illumination of a lamp $(24 \mathrm{~V}, 509 \mathrm{~K}$ bulb) with a $2.54-\mathrm{cm}$ jeweled lens mounted above the right lever. Absence of illumination identified the unsignaled avoidance schedule. Stainless steel $.64-\mathrm{cm}$-diam grid bars, spaced $.127 \mathrm{~cm}$ apart (center to center), were mounted perpendicular to the response levers. Constant-current shock from a Lehigh Valley source was delivered for $.32 \mathrm{sec}$ at $1 \mathrm{~mA}$, with the walls and response levers constituting one contact of the grid circuit.

\section{Procedure}

Subjects were run every other day for 6-h sessions. Throughout the experiment, with either signaled or unsignaled avoidance, the following intervals remained the same: response-shock = $20 \mathrm{sec}$, shock-shock $=5 \mathrm{sec}$, response-signal $=15 \mathrm{sec}$, and signal-shock $=5 \mathrm{sec}$. Subjects avoided shocks on one lever (right) and changed to signaled avoidance on a separate lever (left). Failure to respond for $20 \mathrm{sec}$ initiated the shock-shock interval which continued in effect until a response was made. In the signaled condition, each response reset the response-shock timer, while failure to respond for $15 \mathrm{sec}$ resulted in the onset of the signal. A response in the presence of the signal terminated it and reset the response-shock timer. If no response was made for $5 \mathrm{sec}$, the signal terminated with shock and initiated the shock-shock interval. When in a changeover condition, the first response on the changeover lever resulted in the immediate onset of the correlated stimulus and the schedule switched from unsignaled to signaled avoidance for a fixed period of time.

Initial training and baseline. Subjects were first trained on signaled avoidance. During these sessions (at least three),

\section{A 85}

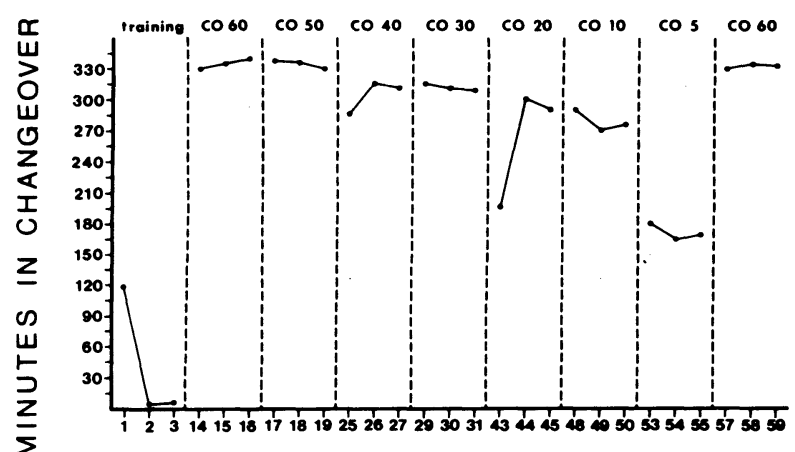

SIX HOUR SESSIONS

A 87

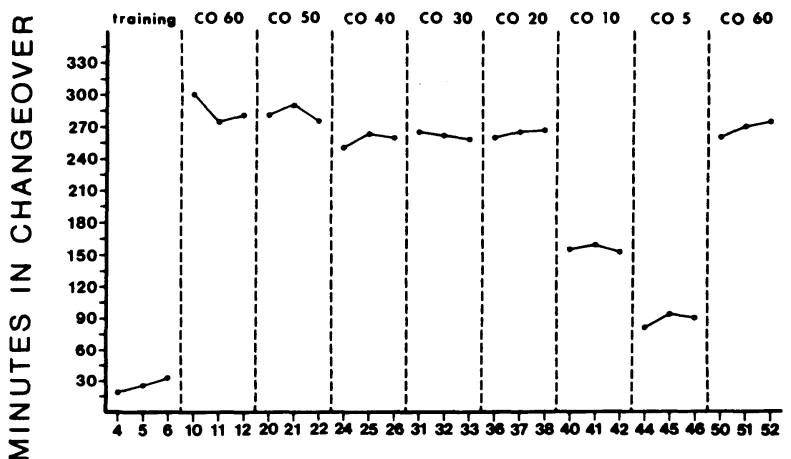

SIX HOUR SESSIONS responses on the changeover lever and the "total session time spent in signaled avoidance" were recorded, although the changeover lever was not functional.

Changeover to signaled avoidance (CO 60). After avoidance responding stabilized and a stable operant level on the changeover bar was obtained, subjects began subsequent sessions in the unsignaled condition. Under the unsignaled condition, a response on the changeover bar produced the correlated stimulus for a 60 -sec period during which the signaled avoidance schedule was in effect. Further responses on the changeover bar did nothing until the $60 \mathrm{sec}$ had timed out. At this time, the subject could reinstate the 60 -sec changeover period or remain in the unsignaled schedule.

Varied durations of changeover periods (CO X). After establishing a baseline of changeover responding at $60 \mathrm{sec}$, the duration of these periods was decreased in 10 -sec steps to a $10-\mathrm{sec}$ period. A final reduction to a 5 -sec period occurred for three subjects. All subjects were then returned to the original 60 -sec changeover period condition. One subject (A85) was run through the entire series again and one subject (A88) received the 5 -sec changeover period condition as additional replications.

\section{RESULTS}

The total duration of time per session spent in the signaled avoidance condition can be seen in Figure 1. It is clear that all subjects chose signaled over unsignaled

\section{A 86}
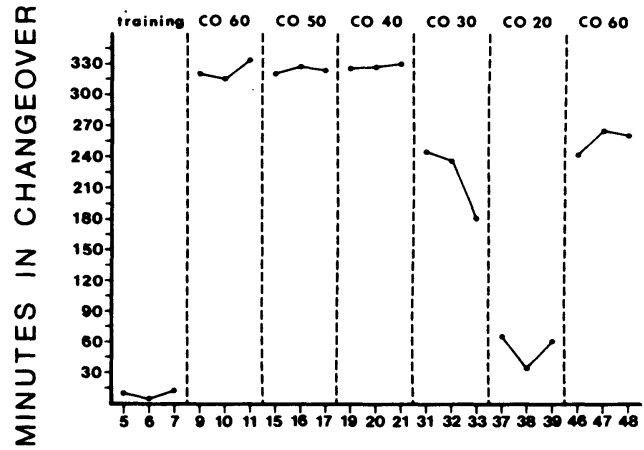

\section{SIX HOUR SESSIONS}

A88

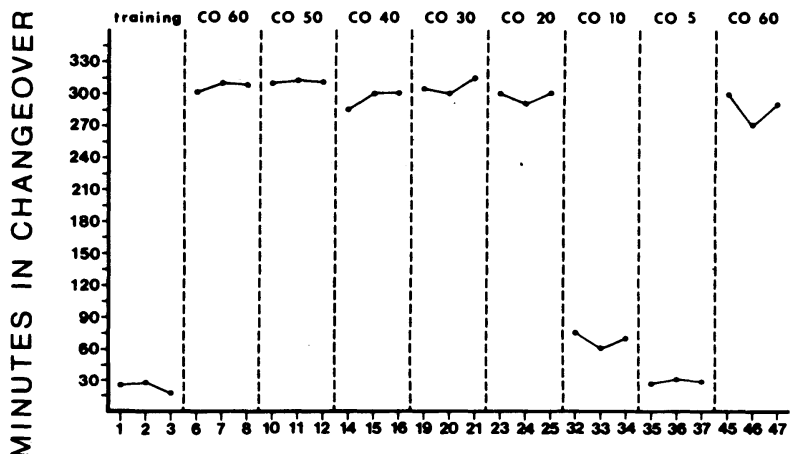

SIX HOUR SESSIONS

Figure 1. The total time per session that individual subjects spent in the signaled avoidance schedule at each signaled period duration. Only the last three or four 6h sessions are shown. For Subject A86, the lines marked " 1 " are the initial exposures and those marked " 2 " are the replications. 
avoidance. As seen in Figure 1, each subject had an initial low operant level on the changeover lever under baseline (initial training) conditions. When the changeover contingency was made effective, changeover responding increased and all subjects spent most of the 6-h sessions in signaled avoidance. Subjects A85 and A86 spent about 330 of $360 \mathrm{~min}$ in the signaled avoidance condition, while Subjects A87 and A88 spent around $300 \mathrm{~min}$ in this condition. The degree of stimulus control acquired by the correlated stimulus was strong. In general, only one changeover response was made to reinstate the changeover condition once it had timed out. Very few "extra" changeover responses were made.

As shown in Figure 1, all subjects except A86 continued changing to the signaled schedule until the changeover duration was reduced to below $20 \mathrm{sec}$ (CO 20). When switched from a 20-sec to a 10-sec changeover period (CO 10), subjects decreased their time in the signaled condition. (The performance of Subject A86 deteriorated at $30 \mathrm{sec}$ and this subject ceased changeover responding at $20 \mathrm{sec}$.) All three subjects showed a substantial decrease in the time spent under signaled avoidance when the changeover duration was further reduced to $5 \mathrm{sec}(\mathrm{CO} 5)$, as Figure 1 shows. Subjects A87 and A88 clearly spent most of the time in the unsignaled avoidance schedule. Event records showed that changeover responses were made only sporadically by these subjects. Subject A85, on the other hand, still continued to respond at a moderate rate.

All subjects returned to their prior high level of changeover responding when the initial 60-sec changeover period was reinstated (Figure 1). Data from the replication of conditions for Subjects A85 and A88 were similar to the initial data, as seen in Figure 1, and will not be discussed further. The rate of avoidance responding varied among subjects but was stable for each condition within each subject. Subject A85 tended to increase rate of avoidance responding across conditions, while A87's rate remained about the same. Both A86 and A88 tended to decrease avoidance responding as the duration of the changeover periods decreased.

As the duration of changeover periods decreased, shock rate in all subjects except A85 tended to increase. Subject A85 had a generally low shock rate which remained relatively constant across conditions except at $\mathrm{CO} 40 \mathrm{sec}$ and $\mathrm{CO} 30 \mathrm{sec}$, where the number of shocks increased slightly. The number of signals per session tended to decrease as changeover duration decreased. It can be seen in Figure 1 that subjects maintained a similar level of changeover time even though the number of signals received per session varied among subjects. In the $\mathrm{CO} 60$-sec condition, for example, Subject A88 spent a slightly greater period of time in the signaled schedule than Subject A87, yet received less than half the number of signals.

\section{DISCUSSION}

The data clearly indicate that subjects will continue to change over for periods of signaled avoidance much less than the 60-sec period used by Badia et al. (1971). Three of the four subjects in the present experiment continued to emit changeover responses until the duration of changeover periods dropped below $20 \mathrm{sec}$. The other subject continued until the duration dropped below $30 \mathrm{sec}$. The decrease in changeover duration coupled with the little drop in total changeover time indicates that the reinforcement for changeover responding is durable over a relatively wide range of intervals. Even with a decrease to one third of the original 60 -sec period, subjects maintained a high rate of changeover responding.

The findings bear upon the interpretation of changeover responding offered by Badia et al. (1971). These investigators found that changeover responses extinguished more quickly and completely when they produced only the signal than when they produced only the stimulus correlated with the signaled schedule. They speculated that the reinforcement for avoidance responding was not only the termination of aversive or fear stimuli (Rescorla \& Solomon, 1967), if such is the case, but the onset of a stimulus which identified a period of time relatively free from shock (safe period). Others have offered similar interpretations (e.g., Seligman, 1968; Weisman \& Litner, 1969). Badia et al. placed particular emphasis on the fact that the correlated stimulus in the absence of the signal identified a shock-free period, while the presence of the signal identified a shock period. In contrast to the signaled schedule, the unsignaled schedule had no identifiable periods of shock and shockfree time. Therefore, reinforcement for changeover responding was said to be the identification of the shock-free periods provided by the signaled condition. Relating this to the present experiment, it must be concluded that the stimulus correlated with the signaled schedule gained sufficient control to reinforce changeover responses even at relatively short changeover durations. If this analysis is correct, it may help explain why two subjects maintained moderate responding at values of $\mathrm{CO} 10$ and $5 \mathrm{sec}$ even though very few signals were received at these values. When a changover response was made, the result was the immediate onset of the correlated stimulus which, in the absence of a signal, identified the shock-free period.

It is still necessary to account for the decrement in changeover responding at the shorter changeover periods. One possibility is effort. Both avoidance responses and changeover responses increased as the changeover period decreased. The increase in the number of changeover responses was obviously related to the decreases in changeover duration. An effort interpretation merely suggests that this increased response requirement eventually reaches a point of being more aversive than staying in the unsignaled schedule.

Effort may not be the only factor, since both shock rate and the total number of signals received varied also. Of these, the most obvious is that of shock rate. Each subject that showed deterioration in changeover performance also showed increases in shock rates. Attempting to attend to both the avoidance and changeover levers at the shorter changeover durations obviously was not an efficient strategy, since shock rate increased at these durations. Perhaps because of this, changeover responding showed a marked decrease at the shorter changeover durations. The data of Subject A85 supports this interpretation. This subject had a relatively constant shock rate throughout the experiment, and it was this subject who was least affected by decreasing the $\mathrm{CO}$ duration.

\section{REFERENCES}

Badia, P., Culbertson, S., \& Lewis, P. The relative aversiveness of signaled vs. unsignaled avoidance: An analysis of preference. Journal of the Experimental Analysis of Behavior, 1971, 16, 113-121.

KEEHN, J. D. The effect of a warning signal on unrestricted avoidance behavior. British Journal of Psychology, 1959, 50, 125-135.

Rescorla, R. A., \& Solomon, R. L. Two-process learning theory: Relationships between Pavlovian conditioning and 
instrumental learning. Psychological Review, 1967, 74, 151-182.

Seligman, M. E. P. Chronic fear produced by unpredictable electric shock. Journal of Comparative and Physiological Psychology, 1968, 66, 402-411.

Sidman, M. Some properties of the warning signal in avoidance behavior. Journal of Comparative and Physiological Psychology, 1955, 48, 444-450.

Ulrich, R. E., Holz, W., \& AzRin, N. H. Stimulus control of avoidance behavior. Journal of the Experimental Analysis of Behavior, 1964, 7, 129-133.

Weisman, R. G., \& Litner, J. S. Positive conditioned reinforcement of Sidman avoidance behavior. Journal of Comparative and Physiological Psychology, 1969, 68, 597-603.

(Received for publication August 10, 1976.) 